\title{
Ferritin immobilization on patterned poly(2-hydroxyethyl methacrylate) brushes on silicon surfaces from colloid system
}

\author{
Tsung-Yen Chen $\cdot$ Jem-Kun Chen
}

Received: 25 October 2010 /Revised: 21 December 2010 /Accepted: 28 December 2010 /Published online: 21 January 2011

(C) The Author(s) 2011. This article is published with open access at Springerlink.com

\begin{abstract}
In this paper, we describe a graft polymerization/ solvent immersion method for generating poly(2-hydroxyethyl methacrylate) (PHEMA) brushes in various patterns. We used a novel fabrication process, involving very-largescale integration and oxygen plasma treatment, to generate well-defined patterns of polymerized PHEMA on patterned $\mathrm{Si}$ (100) surfaces. We observed brush- and mushroom-like regions for the PHEMA brushes, with various pattern resolutions, after immersing wafers presenting lines of these polymers in $\mathrm{MeOH}$ and $n$-hexane, respectively. The interaction between PHEMA and ferritin protein sheaths in $\mathrm{MeOH}$ and $n$-hexane (good and poor solvent for PHEMA, respectively) was used to capture and release ferritins from fluidic system. The "tentacles" behaver for PHEMA brushes was found through various solvents in fluidic system. Using high-resolution scanning electron microscopy, we observed patterned ferritin Fe cores on the Si surface after pyrolysis of the patterned PHEMA brushes and ferritin protein sheaths, which verify the "tentacles" behaver for PHEMA brushes.
\end{abstract}

Keywords PHEMA brush · Nanolithography · Ferritin

\section{Introduction}

Combining atom transfer radical polymerization (ATRP) with surface-initiated graft polymerization allows controlled grafting of well-defined polymers, with dramatically high

T.-Y. Chen · J.-K. Chen $(\bowtie)$

Department of Materials Science and Engineering,

National Taiwan University of Science and Technology,

43, Sec 4, Keelung Rd,

Taipei 106 Taiwan, Republic of China

e-mail: jkchen@mail.ntust.edu.tw surface densities, onto various solid surfaces [1, 2]. Surfaceinitiated ATRP (SI-ATRP) is an effective method for the production of biomedically and biotechnologically interesting brushes [3, 4]. SI-ATRP has been used to prepare "nonfouling" poly[oligo(ethylene glycol) methacrylate] and poly(2-methacryloyloxyethyl phosphorylcholine) brushes that effectively resist protein and cell adhesion $[[5,6]]$. In addition, polymer brushes based on $N$-isopropylacrylamide exhibit lower critical solution temperature behavior: they can be switched reversibly from a hydrophilic, biologically inert state to a hydrophobic, protein- and cell-adhesive state, merely by changing the temperature [7].

Stable polymer brushes can provide excellent mechanical and chemical protection to a substrate, alter the electrochemical characteristics of an interface, and provide new pathways for the functionalization of Si surfaces [3, 8, 9]. One particular advantage that polymer brushes have over spin-coated polymer layers is their stability against solvents or harsh conditions (e.g., high temperatures), resulting from their covalent bonding to the substrates. Concentrated brushes have structures and properties that are quite different, and even unpredictable, from those of semidilute brushes; most strikingly, poly(methyl methacrylate) (PMMA) concentrated brushes swollen in a good solvent (toluene) exhibited an equilibrium film thickness as large as $80-90 \%$ of the full (contour) length of the graft chains, indicating that the chains were extended to a similarly high degree [10]. A surface density of 0.7 chains per square nanometer for a PMMA brush, for example, also means that the thickness of the dry film reaches approximately $40 \%$ of the full length of the chains - much larger than the mean size of the chains in a random-coil ("mushroom") conformation [11].

Advances in biomedicine and biotechnology have led to an increasing demand for materials that can undergo specific biological interactions with their environment, 
thereby requiring novel surface functionalization strategies. Functionalization of Si surfaces with organics is emerging as an important area for the development of new Si-based devices, such as optical tweezers [12, 13] systems and DNA- [14] and protein-based biochips and biosensors [15]. The use of polymers as building blocks for surface modification allows the preparation of "smart" or responsive surfaces that operate based on conformational changes in the polymer backbones. One attractive strategy involves the application of a thin biologically inert polymer coating that can subsequently be used as a platform to introduce biologically active molecules. The adsorption and immobilization of proteins from aqueous solutions onto solid surfaces are among the most important problems in biochemical research. Many biotechnological processes require immobilization of enzymes with full retention of their biological activity $[16,17]$. On the other hand, unspecific adsorption of proteins must be suppressed in many practical applications in order to prevent biofouling [18]. Very often, charged and uncharged polymers attached to surfaces are used to tune the interaction with proteins. Tethered chains of poly(ethylene oxide) are now widely used to prevent protein adsorption [19] while polyelectrolyte multilayers $[20,21]$ or dense layers of polyelectrolytes $[21,22]$ are utilized to immobilize proteins on surfaces. The interactions between proteins and brush-coated surfaces can be modeled using three generic modes [23]: primary adsorption, in which a protein diffuses into the brush and adsorbs on the substrate surface; secondary adsorption, which occurs at the outermost surface of the swollen brush film; and tertiary adsorption, which is caused by interaction of a protein with polymer segments within the brush layer. For relatively small proteins, primary and tertiary adsorptions are particularly important; they become less important upon increasing the protein size and the graft density because a larger protein would have greater difficulty diffusing against the concentration gradient formed by the polymer brush - and this gradient, clearly, is a function of grafting density. The size and density dependence of protein adsorption would, however, manifest itself much more clearly for concentrated brushes, due to a different mechanisms [24]. In a previous study, we used polymerization to chemically amplify surfaces patterned with a verylarge-scale integration (VLSI) system into patterned polymer brushes [25]. After immersion in water and $n$-hexane, we observed distinct brush- and mushroom-like structures, respectively, for the polymer brushes patterned into lines. In this study, we patterned PHEMA brush as a medium to adsorb and conceal the ferritins from the modified surface through brush- and mushroom-like regions of PHEMA brush in water (a good solvent for PHEMA) and $n$-hexane (a poor solvent for PHEMA). To investigate the concealment of ferritins, the samples were subjected to $\mathrm{O}_{2}$ at $500{ }^{\circ} \mathrm{C}$ to remove the patterned PHEMA brushes and ferritin protein sheaths from the surface. We observed the distribution of the Fe cores to establish the adsorption mechanisms for ferritin in the mushroom- and brush-like regimes of the PHEMA brushes on the substrate surface.

\section{Experimental section}

\section{Materials}

Single-crystal Si wafers, $\mathrm{Si}(100)$, polished on one side (diameter of 6 in.), were supplied by Hitachi, Inc. (Japan), and cut into $2 \mathrm{~cm} \times 2 \mathrm{~cm}$ samples. The initiator, 11-(2bromo-2-methyl)propionyloxyundecyltrichlorosilane (BPOTS), was ordered from HRBio (China). The materials used for graft polymerization, 2-hydroxyethyl methacrylate (HEMA), copper(I) bromide, copper(II) bromide, and 2,2'bipyridine (Bip), were purchased from Acros Organics. HEMA, Bip, and BPOTS were purified through vacuum distillation prior to use. Ferritin (diameter of $13 \mathrm{~nm}$; Fe core diameter of $7 \mathrm{~nm}$ ), a protein found in most organisms and obtained from MP Biomedicals, functions principally to sequester excess $\mathrm{Fe}$ from cells. Ferritin has diameter of $12.0 \mathrm{~nm}$ and is composed of 2.0-nm-thick protein sheath surrounding a "ferrihydrite" mineral core [26]. The protein sheath comprises 24 individual subunits assembled to give a roughly spherical quaternary structure. The threefold sites of contact form the hydrophilic channels through which $\mathrm{Fe}$ enters the protein [27]. All other chemicals and solvents were of reagent grade and purchased from Aldrich. All solvents were of reagent grade and used without further purification. To remove dust particles and organic contaminants, the $\mathrm{Si}$ surfaces were ultrasonically rinsed sequentially with $\mathrm{MeOH}$, acetone, and dichloromethane for $10 \mathrm{~min}$ each and then dried under vacuum. The Si substrates were immersed in hydrofluoric acid (HF) solution (50 wt.\%) for $5 \mathrm{~min}$ at room temperature to remove the silicon oxide film. The HF-treated substrates were immersed in a mixture of $\mathrm{HNO}_{3}$ and $\mathrm{H}_{2} \mathrm{O}_{2}(2: 1 \mathrm{~mol} \%)$ for $5 \mathrm{~min}$ and then rinsed with doubly distilled water at least five times to oxidize the $\mathrm{Si}$.

\section{Synthesis of initiator-modified Si surface}

The basic strategy for the fabrication of the patterned polymer brushes using the VLSI process has been described previously [24]. The fabrication of the patterned HEMA brushes using the VLSI process is depicted as shown in Scheme 1. In Scheme 1 (a), the Si wafer was treated with hexamethyldisilazane (HMDS) in a thermal evaporator (Track MK-8) at $90{ }^{\circ} \mathrm{C}$ for $30 \mathrm{~s}$ to transform the $\mathrm{OH}$ groups on the surface of the wafer into an inert film of $\mathrm{Si}$ $\left(\mathrm{CH}_{3}\right)_{3}$ groups. In Scheme 1 (b), The photoresist was spun 
Scheme 1 Synthetic route toward PHEMA brushes patterned through OPT, advanced lithography, and ATRP on Si wafers

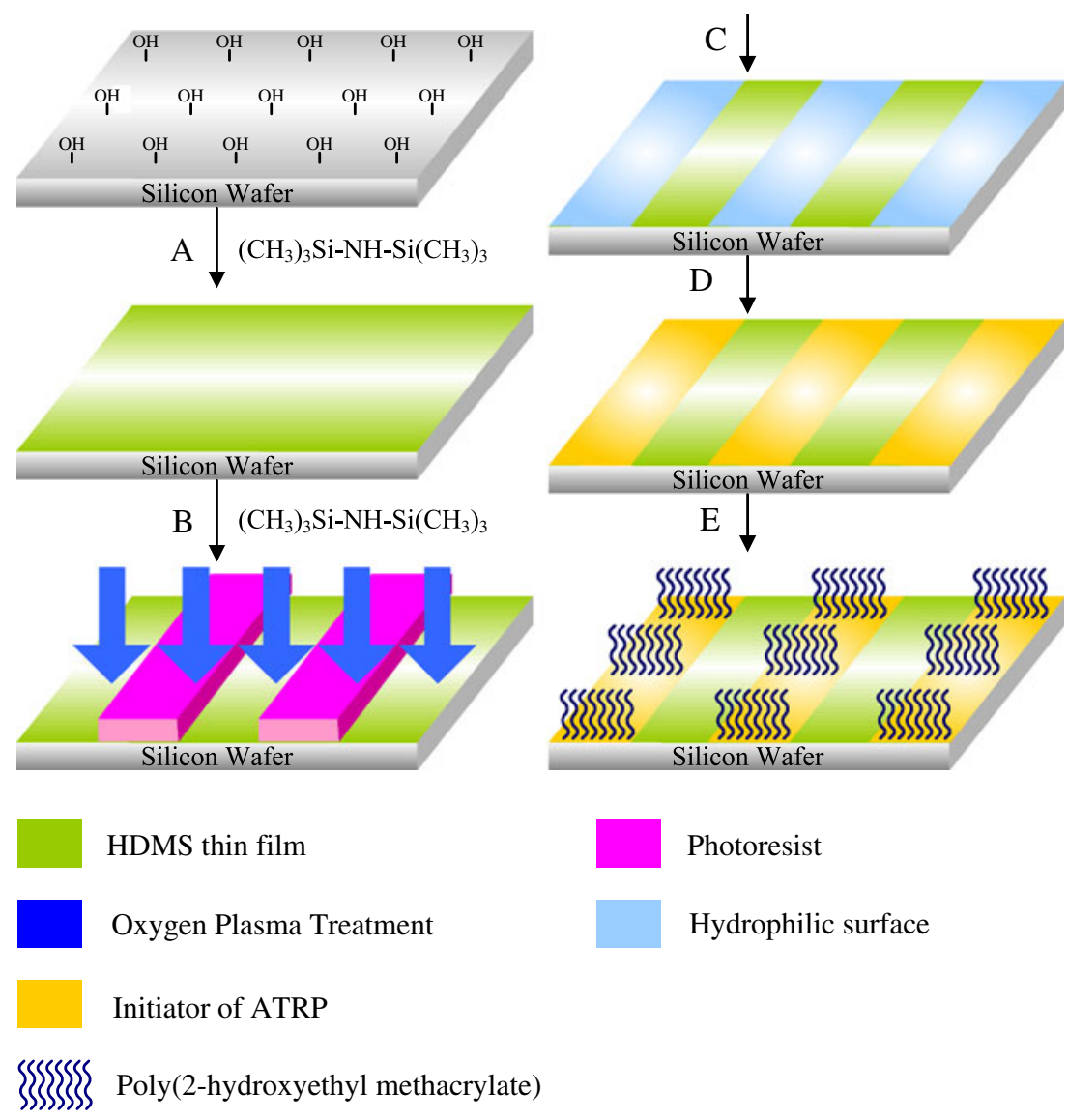

on the HMDS-treated Si wafer at a thickness of $780 \mathrm{~nm}$. Advanced lithography was then used to pattern the photoresist with an array of trenches having dimensions ranging from $200 \mathrm{~nm}$ to $10 \mu \mathrm{m}$ after development. In Scheme 1 (c), the sample was then subjected to oxygen plasma treatment (OPT) using a TCP 9400SE instrument (Lam Research Co, Ltd.) to form $\mathrm{OH}$ groups from the HMDS-treated surface. The plasma power supply was set to $300 \mathrm{~W}$ at a frequency of $13.5 \mathrm{MHz}$. The substrate was placed on the bottom electrode with the $\mathrm{Si}(100)$ surface exposed to the glow discharge at an $\mathrm{O}_{2}$ pressure of approximately $5 \times 10^{-3}$ Torr for a predetermined period of time to form peroxide and hydroxide species for the subsequent graft polymerization experiment. OPT caused the surface to become chemically modified (strongly hydrophilic or polar) only in the areas not covered by the photoresist $[28,29]$. The introduction of these polar groups provided a more wettable surface for the preparation of a self-assembled monolayer (SAM) for graft polymerization. In Scheme 1 (d), the Si substrate treated with HMDS and $\mathrm{O}_{2}$ plasma was immersed in a $0.5 \%(w / v)$ solution of BPOTS in toluene for $3 \mathrm{~h}$ at $50{ }^{\circ} \mathrm{C}$ to immobilize the ATRP initiator (BPOTS). The BPOTS units were assembled selectively onto the bare regions of the Si surface after OPT, where it reacted with $\mathrm{SiO}$ and $\mathrm{SiOO}$ species. This procedure resulted in a surface patterned with regions of BPOTS for ATRP and regions of photoresist. The functionalized $\mathrm{Si}$ substrates were removed from the solution, washed with toluene for $15 \mathrm{~min}$ to remove any unreacted material, dried under a stream of $\mathrm{N}_{2}$, and subjected to surface-initiated polymerization reactions. Finally, the surfaces were dried under vacuum and stored under dry $\mathrm{N}_{2}$. In Scheme 1 (e), the patterned PHEMA brushes were grafted on the initiatormodified Si surface by ATRP.

Surface-initiated atom transfer radical polymerization

HEMA, $\mathrm{CuBr}$ (55 mg, $0.55 \mathrm{mmol}), \mathrm{CuBr}_{2}$, and Bip were added to a mixture of $\mathrm{MeOH}(10 \mathrm{~mL})$ and water $(10 \mathrm{~mL})$. The solution was stirred and degassed with Ar for $20 \mathrm{~min}$, and then the Si-BPOTS substrate was added at room temperature. After various polymerization times, the wafers were placed in a Soxhlet apparatus to remove any unreacted monomer, catalyst, and non-grafted material. The remaining photoresist was removed from the HMDS-treated surface by rinsing with solvent, leaving behind the chemically nanopatterned surface. The surfaces were then dried under vacuum at $80{ }^{\circ} \mathrm{C}$ for $20 \mathrm{~min}$. The polymer-modified $\mathrm{Si}$ surfaces were analyzed using ellipsometry (SOPRA SE-5, France) and X-ray photoelectron spectroscopy (XPS; Scien- 
tific Theta Probe, UK). In addition, samples of "free" PHEMA were synthesized in solution under the same conditions ([HEMA]/[BPOTS]/[CuBr] $/[$ Bip] $=150: 1: 1: 1 ;$ [HEMA] $=$ $2.75 \mathrm{M}$ ) as those used for grafting polymerization to provide polymers having the same molecular weights of PHEMA as the brushes grafted on the Si surface; they were analyzed using gel permeation chromatography (GPC). The monomer conversion was determined gravimetrically. GPC measurements were performed using a VISCOTEK-DM400 instrument equipped with an LR 40 refractive index detector. Monodisperse polystyrene standards (Polymer Lab, Agilent Co.) were used to generate the calibration curve. Although the exact molecular weights of the polymers grafted onto the $\mathrm{Si}$ surface were not known, the molecular weight of the graft polymer was expected to be proportional to that of the polymer formed in solution [30]. The resolutions of the various patterns of lines of PHEMA brushes after solvent treatment were measured using atomic force microscopy (AFM; Veeco Dimension 5,000 scanning probe microscope) and high-resolution scanning electron microscopy (HRSEM; JEOL JSM-6,500 F, Japan).

\section{Surface energy calculation}

Contact angles were measured using a Kruss-G40 contact angle goniometer. The surface energy was evaluated using the Lifshitz-van der Waals acid/base approach (three-liquid acid/base method) proposed by van Oss et al. [31]. This methodology introduces new meanings to the concepts of "apolar" (Lifshitz-van der Waals, $\gamma^{\mathrm{LW}}$ ) and "polar" (Lewis acid/base, $\gamma^{\mathrm{AB}}$ ), where the latter cannot be represented by a single parameter, such as $\gamma^{\mathrm{p}}$. Briefly, the theoretical approach follows the additive concept that had been suggested by Fowkes [32].

$\gamma=\gamma^{\mathrm{d}}+\gamma^{\mathrm{AB}}$

where $\gamma^{\mathrm{d}}$ is the dispersive term of the surface tension. The superscript $\mathrm{AB}$ refers to the acid/base interaction. By regrouping the components in Eq. 1, van Oss et al. expressed the surface energy as

$\gamma=\gamma^{\mathrm{LW}}+\gamma^{\mathrm{AB}}$

Two parameters were created to describe the strength of the Lewis acid and base interactions:

$\gamma_{\mathrm{s}}^{+}$(Lewis) acid parameter of surface free energy

$\gamma_{\mathrm{s}}^{-}$(Lewis) base parameter of surface free energy

$\gamma^{\mathrm{AB}}=2\left(\gamma_{\mathrm{s}}^{+} \gamma_{\mathrm{s}}^{-}\right)^{1 / 2}$
Van Oss, Good, and their co-workers developed a "threeliquid procedure" (Eq. 4) to determine the value of $\gamma_{\mathrm{S}}$ using the contact angle technique.

$$
\gamma_{\mathrm{L}}(1+\cos \theta)=2\left[\left(\gamma_{\mathrm{s}}^{\mathrm{LW}} \gamma_{\mathrm{L}}^{\mathrm{LW}}\right)^{1 / 2}+\left(\gamma_{\mathrm{s}}^{+} \gamma_{\mathrm{L}}^{-}\right)^{1 / 2}+\left(\gamma_{\mathrm{s}}^{-} \gamma_{\mathrm{L}}^{+}\right)^{1 / 2}\right]
$$

To determine the components of $\gamma_{\mathbf{S}}$ of a polymer solid, three liquids are selected: two of them polar and the third apolar. Water/ethylene glycol and water/formamide are polar pairs that give good results. The apolar liquid is usually either diiodomethane or $R$-bromonaphthalene because the LW parameters of the Lewis acid and base are available. The value of $\gamma_{\mathbf{S}}$ of the Lewis acid and base can then be determined by solving the three equations derived from Eqs. 3 and 4 simultaneously. By measuring the contact angles of water, diiodomethane, and ethylene glycol, the values of $\gamma_{\mathrm{L}}{ }^{\mathrm{LW}}, \gamma_{\mathrm{L}}{ }^{+}$, and ${\gamma_{\mathrm{L}}}^{-}$can be obtained [33].

Ferritin capture behavior of the PHEMA brush surface from various fluids

Ferritin (diameter of $13 \mathrm{~nm}$; Fe core diameter of $7 \mathrm{~nm}$; protein shell of $6 \mathrm{~nm}$ ) was obtained from MP Biomedicals. Figure 1 displays the strategy used for ferritin capture. In Fig. 1 (I), the ferritin solution (good solvent for PHEMA brush) was injected into the channel surfaces patterned with PHEMA brushes by micropump. Ferritins adsorbed on the surface for all regions because of the protein shell of ferritins. In Fig. 1 (II), the $n$-hexane (poor solvent for PHEMA brush) was injected sequentially into the channel surface by micropump [34]. To verify the "tentacles" behavior, the samples containing ferritin were treated under a moist environment to remove the protein sheaths through bacterial digestion with Escherichia coli cells; the surface Fe cores aggregated without adhesion, whereas the ferritin units buried within the thin film were protected by the PHEMA brushes under these conditions. The elements of the surfaces were analyzed using XPS (Scientific Theta Probe, UK). The PHEMA brushes and the ferritin protein sheaths buried within them were then pyrolyzed under $\mathrm{O}_{2}$ in an oven at approximately $500{ }^{\circ} \mathrm{C}$ to reveal the ferrihydrite cores. The resolutions of various patterns of lines of PHEMA brushes after solvent treatment were measured using HR-SEM.

\section{Results and discussion}

Characterization of initiator on the HMDS- and OPT-treated Si surface

To prepare polymer brushes on the $\mathrm{Si}$ surface, it was necessary for us to immobilize a uniform and dense layer of 


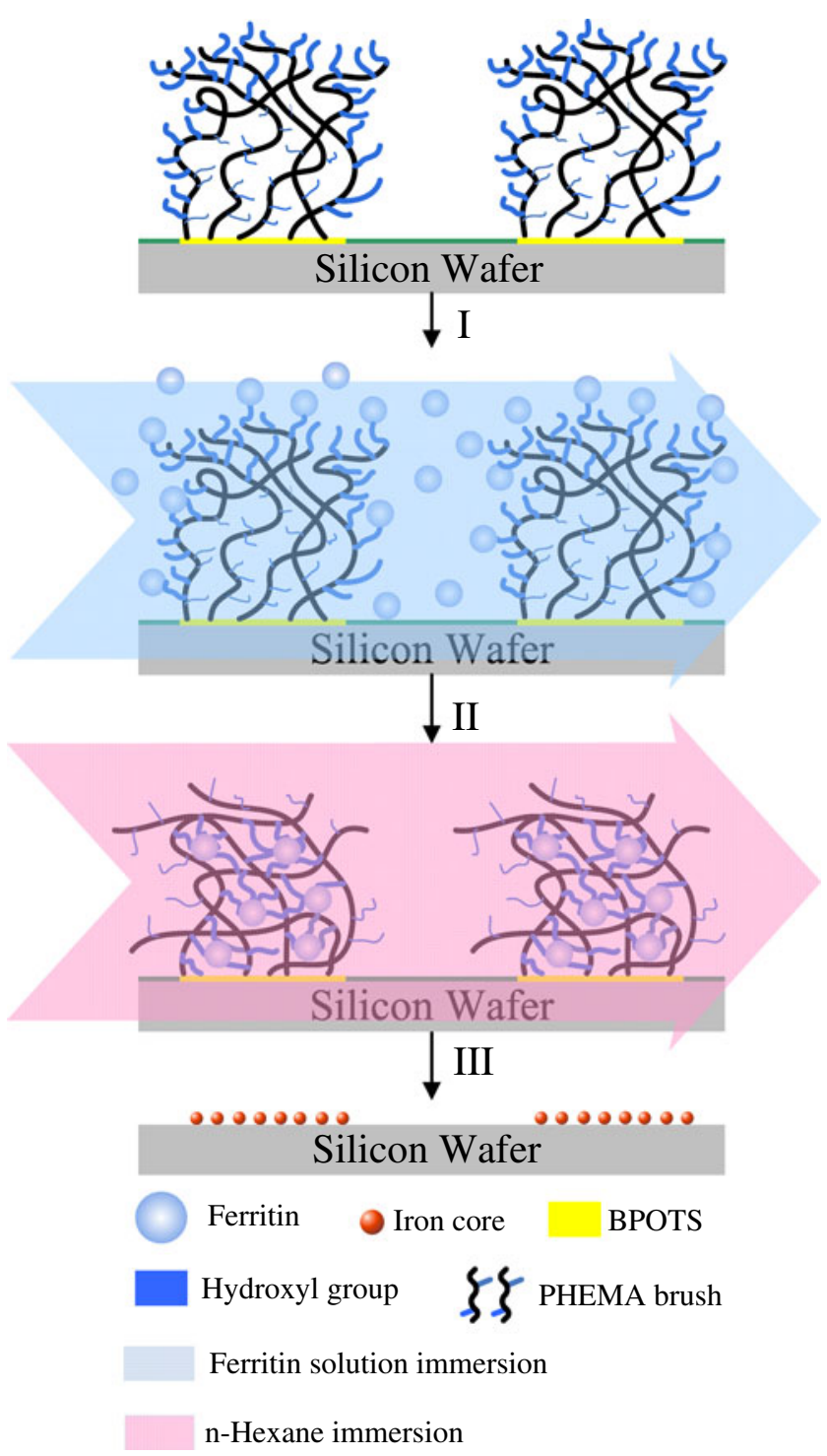

Fig. 1 Schematic representation of the strategy for ferritin capture. (I) The sample surface presenting the patterned PHEMA brushes is immersed for $1 \mathrm{~h}$ into a mixture of water and $\mathrm{MeOH}$ containing dispersed ferritin. (II) The sample surface is immersed into $n$-hexane to transform it from a brush-like to a mushroom-like structure, with the $\mathrm{OH}$ groups of the PHEMA brushes becoming buried within the PHEMA thin film to form hydrophilic domains. (III) The ferritin species on the PHEMA thin-film surface are removed through degradation of the protein sheath under $\mathrm{O}_{2}$ in an oven at approximately $500{ }^{\circ} \mathrm{C}$ to observe the ferrihydrite cores

initiators on the Si surface. The chemical compositions of the pristine $\mathrm{Si}(100)$ surface and the $\mathrm{Si}$ surfaces at various stages during the surface modification process were determined using XPS. Two peak components at binding energies (BE) of approximately 99 and $103 \mathrm{eV}$ (attributable to $\mathrm{Si}-\mathrm{Si}$ and $\mathrm{Si}-\mathrm{O}$ species, respectively) appear in the $\mathrm{Si} 2 \mathrm{p}$ core-level spectrum of the pristine $\operatorname{Si}(100)$ surface (Fig. 2a). Treatment of the pristine Si(100) surface with HMDS passivated the native oxide layer and yielded a $\mathrm{Si}-\mathrm{C}$

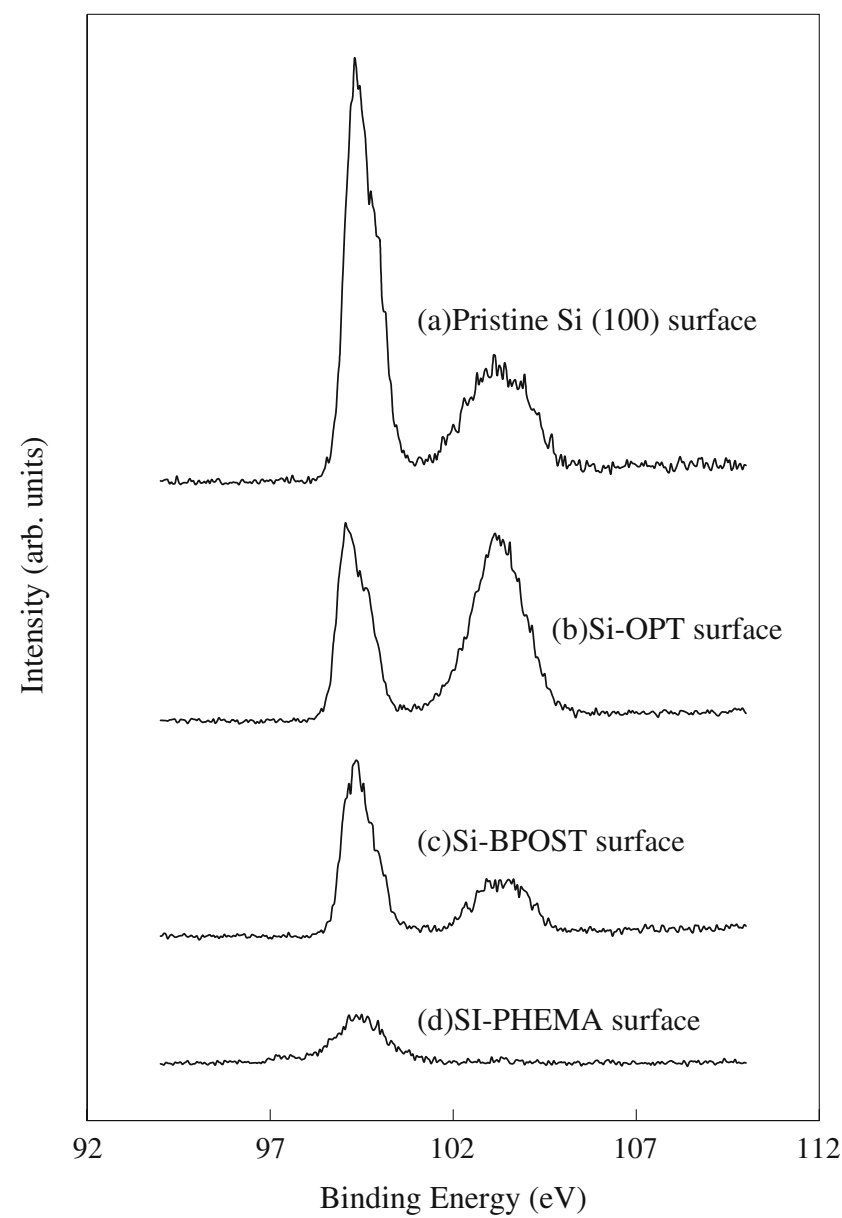

Fig. 2 XPS Si $2 p$ core-level spectra of the surfaces of the a pristine Si (100), b Si-OPT, c Si-BPOTS, and d Si-PHEMA

surface. The disappearance of the signal for the $\mathrm{Si}-\mathrm{O}$ species at a BE of $103 \mathrm{eV}$ confirmed that the Si surface was ideally carbon-terminated after HMDS treatment [35]. OPT of the Si surface removed the $\mathrm{Si}-\mathrm{C}$ layer to activate the $\mathrm{Si}$ surface with $\mathrm{Si}-\mathrm{O}$ species, which appeared as a signal at a $\mathrm{BE}$ of $103 \mathrm{eV}$ in Fig. 2b. The weakened signal for the $\mathrm{Si}-\mathrm{O}$ species at a $\mathrm{BE}$ of $103 \mathrm{eV}$ confirmed that the Si surface was ideally carbon-terminated on the initiator (BPOTS)-functionalized Si surface (Fig. 2c). The disappearance of the signal for the $\mathrm{Si}-\mathrm{O}$ species $(\mathrm{BE}=103 \mathrm{eV})$ and the weakened signal for the $\mathrm{Si}-\mathrm{Si}$ species $(\mathrm{BE}=99 \mathrm{eV})$ on the surface presenting PHEMA brushes confirmed that the $\mathrm{Si}$ surface was ideally covered with the grafted PHEMA layer (Fig. 2d). Figure 3 displays the $\mathrm{O} 1 \mathrm{~s}$ core-level spectra of the $\mathrm{Si}-\mathrm{OH}$ surface after subjecting the pristine $\mathrm{Si}(100)$ surface to OPT for $20 \mathrm{~s}$. The $\mathrm{O}$ element component increases from $31 \%$ to $65 \%$, indicating the increased abundance of $\mathrm{OH}$ groups on the Si-OPT surface after OPT. Figure 4a displays the C 1s core-level spectra of the $\mathrm{Si}-\mathrm{OH}$ surface after being subjected to BPOTS treatment. We curve-fitted the $\mathrm{C} 1 \mathrm{~s}$ core-level spectra of the initiator (BPOTS)-functionalized Si surfaces to three peak compo- 


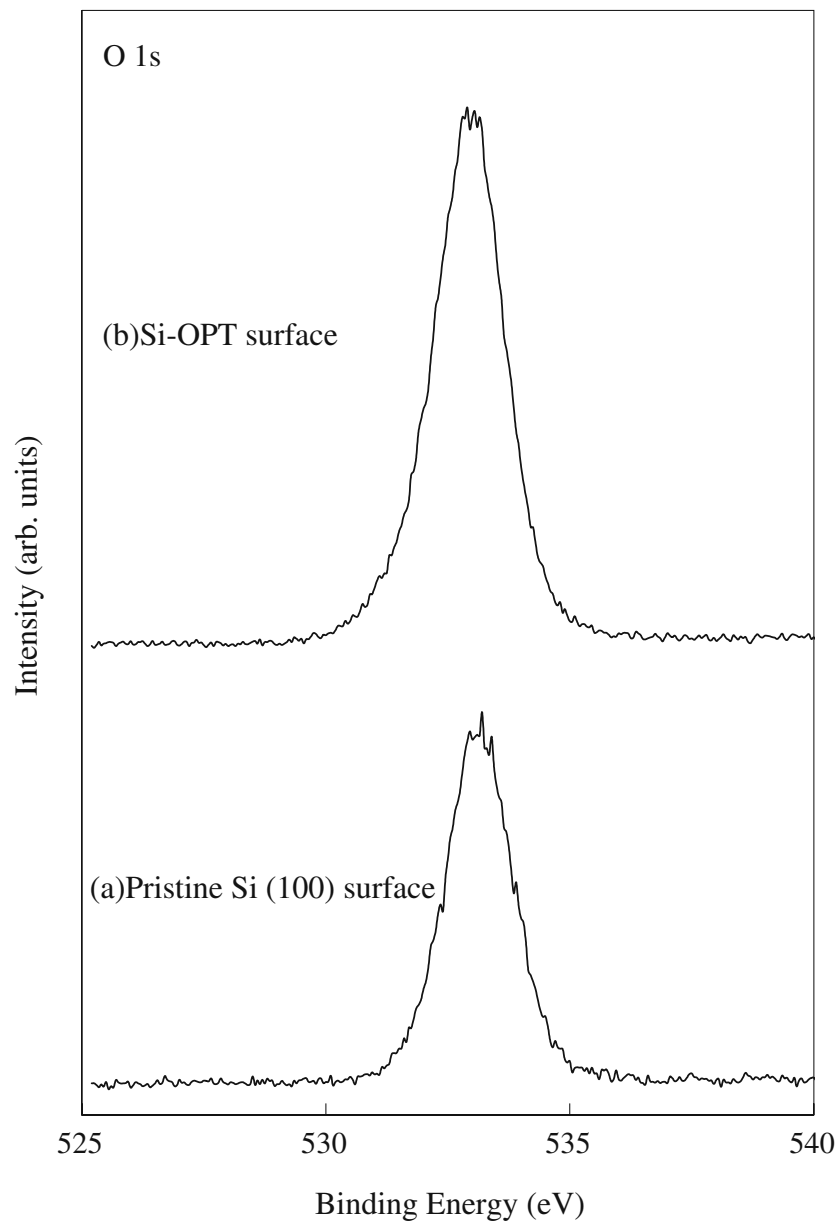

Fig. 3 XPS O 1s core-level spectra of the surfaces of the a pristine $\mathrm{Si}$ (100) and b Si-OPT

nents having BEs of approximately 284.2, 285.7, and $288.8 \mathrm{eV}$, attributable to $\mathrm{C}-\mathrm{H}, \mathrm{C}-\mathrm{O}$, and $\mathrm{O}=\mathrm{C}-\mathrm{O}$ species, respectively. Additionally, the presence in the $\mathrm{Br} 2 \mathrm{p}$ corelevel spectrum of a signal at a BE of approximately $72.6 \mathrm{eV}$ for the BPOTS-functionalized Si surface (Fig. 4b) indicated that the BPOTS species had been immobilized successfully on the Si surface.

The $\mathrm{O} / \mathrm{Si}$ ratio was determined from the sensitivityfactor-corrected C 1s, O 1s, and Si 2p core-level peak area ratios obtained at a photoelectron takeoff angle $(R)$ of $75^{\circ}$. The $\mathrm{C} / \mathrm{Si}$ ratio decreased and the $\mathrm{O} / \mathrm{Si}$ ratio increased upon increasing the OPT time. Furthermore, the values of the $[\mathrm{O}] /[\mathrm{Si}]$ and $[\mathrm{C}] /[\mathrm{Si}]$ ratios of the Si-HMDS surface obtained from XPS analysis were 0.4 and 2.6, respectively -in fairly good agreement with the theoretical ratios of 0.5 and 3 , respectively. Fairly good agreements also existed between the XPS-derived and theoretical surface compositions of the Si-OPT and Si-BPOTS grafted Si surfaces with respect to those from a previous study [20]. Plasma is used extensively for the treatment of Si wafers, especially for surface cleaning and etching. The idea behind OPT is to create a very reactive gas environment enclosed in a vacuum. Surfaces in contact with the plasma experience interactions that may result in sputtering and chemical reactions caused by highly reactive radicals, low-energy ions, and electrons created in the plasma. Because the chemical properties of Si resemble those of carbon, it can be deduced that OPT of a $\mathrm{Si}$ surface, followed by atmospheric exposure, can also introduce some active oxygen species, such as the $\mathrm{SiO}$ and $\mathrm{SiOO}$ units, that increase the $\mathrm{O} / \mathrm{Si}$ ratio. In subsequent experiments, we used these active oxygen species for reactions with the initiator of graft polymerization. The introduction of polar groups through OPT also provided a more wettable surface. Thus, the Si-OPT surface possessed the highest surface energy
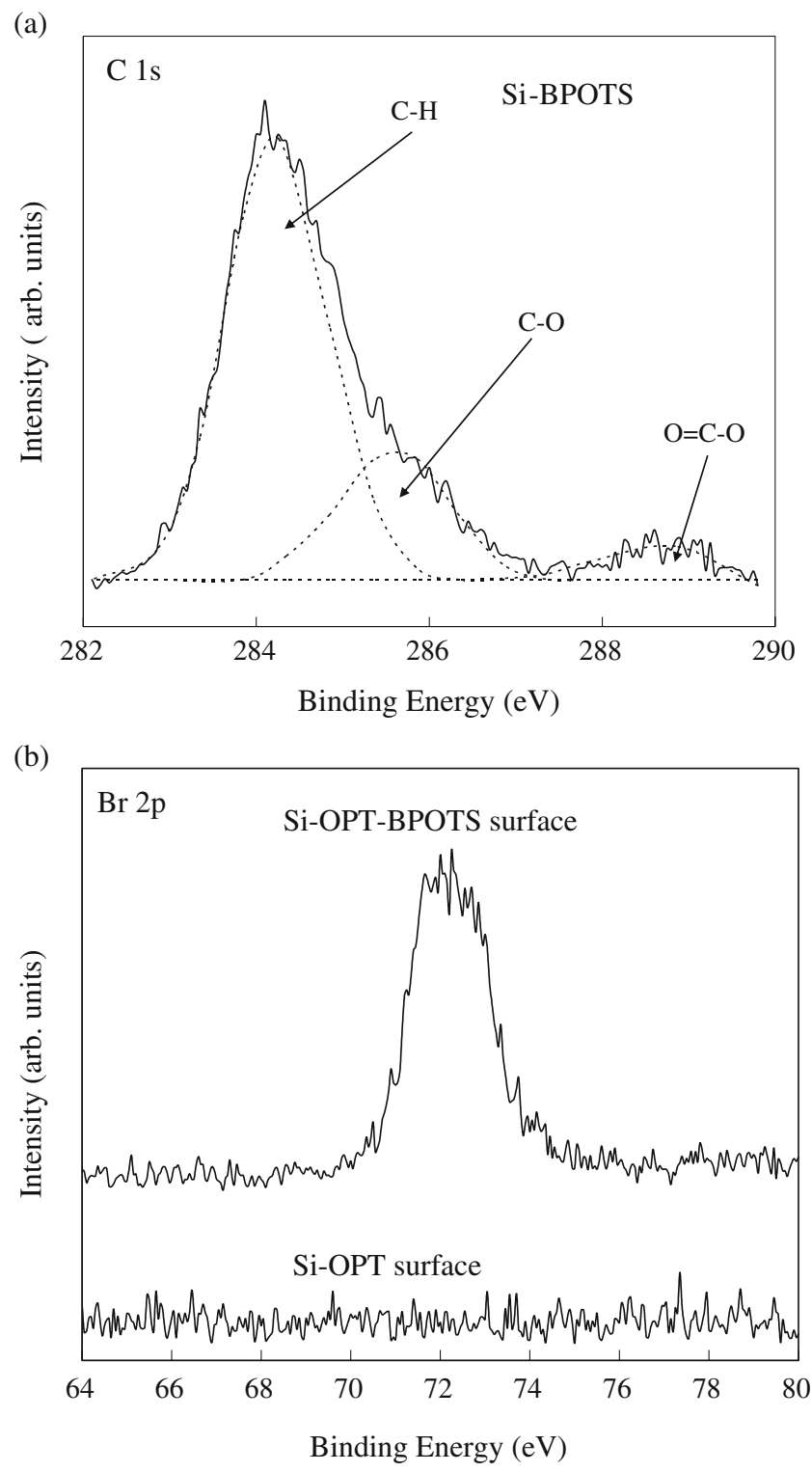

Fig. 4 a XPS C 1s core-level spectrum of the Si-BPOTS surface. b XPS $\mathrm{Br} 2 \mathrm{~d}$ core-level spectra of the Si-BPOTS and Si-OPT surfaces 
Table 1 Surface tension parameters calculated from the advancing contact angles for water, diiodomethane (DIM), and ethylene glycol (EG) on Si-BPOTS and Si-PHEMA films

\begin{tabular}{|c|c|c|c|c|c|c|c|c|c|c|c|}
\hline \multirow[t]{2}{*}{ Sample } & \multicolumn{2}{|c|}{ Chemical composition } & \multicolumn{3}{|c|}{ Contact angle $\left( \pm 3^{\circ}\right)$} & \multicolumn{5}{|c|}{ Surface energy (mN/m) } & \multirow[t]{2}{*}{ Film thickness $( \pm 0.5 \mathrm{~nm})$} \\
\hline & {$[\mathrm{O}] /[\mathrm{Si}]^{\mathrm{a}}$} & {$[\mathrm{C}] /[\mathrm{Si}]^{\mathrm{b}}$} & water & DIM & EG & $\gamma^{\mathrm{LW}}$ & $\gamma^{+}$ & $\gamma^{-}$ & $\gamma^{\mathrm{AB}}$ & $\gamma$ & \\
\hline Si-BPOTS & $2.3(2)$ & $10.2(14)$ & 84.2 & 51.9 & 58.3 & 33.2 & 0.1 & 5.1 & 1.4 & 34.6 & 4.2 \\
\hline Si-BPOTS-PHEMA & - & - & 73.3 & 41.9 & 58.3 & 38.6 & 0.1 & 14.8 & 2.4 & 41.1 & - \\
\hline
\end{tabular}

${ }^{a}$ Determined from XPS core-level spectral area ratio. Values in parentheses are theoretical ratios

${ }^{\mathrm{b}}$ Determined from the XPS curve-fitted C 1s core-level spectra. Values in parentheses are theoretical ratios

because of the $\mathrm{OH}$ groups that had been introduced during the OPT process. In addition, the water contact angle of the Si-HMDS surface was approximately $51.3^{\circ}$; after OPT, the water contact angle decreased to approximately $23.5^{\circ}$; immobilization of BPOTS on the $\mathrm{Si}$ surface provided a water contact angle of approximately $84.2^{\circ}$. The variation in contact angles of these $\mathrm{Si}$ surfaces indicates that the hydrophilicity of the Si surface was readily tuned. Table 1 summarizes the surface analysis and surface energy data for the Si-BPOTS and Si-PHEMA surfaces. The $[\mathrm{O}] /[\mathrm{Si}]$ and $[\mathrm{C}] /[\mathrm{Si}]$ ratios of the Si-BPOTS surface, obtained through XPS analysis, were 2.3 and 10.2, respectively-in fairly good agreement with their theoretical ratios of 2 and 14, respectively. Fairly good agreements also existed between the XPS-derived and theoretical surface compositions of the Si-BPOTS grafted Si surfaces [24].

Brush- and mushroom-like patterned PHEMA brush structures on Si surfaces

In a previous study, we used XPS analysis to investigate the presence of grafted PHEMA brushes on Si surfaces [28]. The $\mathrm{C}$ 1s core-level spectrum of the PHEMA brushes on the Si surface could be curve-fitted to three peak components having BEs of approximately 284.6, 286.4, and $288.8 \mathrm{eV}$, attributable to $\mathrm{C}-\mathrm{H}, \mathrm{C}-\mathrm{O}$, and $\mathrm{O}=\mathrm{C}-\mathrm{O}$ species, respectively. For the HEMA homopolymer, the theoretical $[\mathrm{O}] /[\mathrm{C}]$ and $[\mathrm{CH}] /[\mathrm{C}-\mathrm{O}] /[\mathrm{O}=\mathrm{C}-\mathrm{O}]$ ratios are 0.5 and $4: 1: 1$, respectively. The corresponding ratios of 0.46 and 3.7:1.1:1, respectively, obtained through XPS analysis of the Si-BPOTS-PHEMA surface, are in fairly good agreement with the theoretical ratios. The Si surface presenting the PHEMA graft layer exhibited a water contact angle of approximately $73.3^{\circ}$, which is equivalent to a surface energy of $41.1 \mathrm{mN} / \mathrm{m}$ (Table 1) [36]. Because ATRP is a "living" polymerization process, we expected that the thickness of the polymer brushes would increase linearly upon increasing the polymerization time and the molecular weight of the graft polymer. We found, however, that the thickness of the PHEMA brushes was affected by whether it had been immersed in $n$-hexane or $\mathrm{MeOH}$. Figure 5 displays the thicknesses of the PHEMA brushes grafted for various times onto the Si-BPOTS surfaces, recorded after ultrasonication in $n$-hexane or $\mathrm{MeOH}$ for $3 \mathrm{~h}$. We observe approximately linear increases in thickness of the grafted PHEMA layer on the Si-BPOTS surface upon increasing the polymerization time to $12 \mathrm{~h}$, after immersion in either $n$ hexane or $\mathrm{MeOH}$. The thickness reached a plateau, indicating the formation of mushroom-like regimes of PHEMA brushes, after poor solvent ( $n$-hexane) immersion of the polymer obtained after polymerization for more than $12 \mathrm{~h}$ (filled squares). In contrast, the thickness of the PHEMA brushes grafted on the $\mathrm{Si}$ substrate after $\mathrm{MeOH}$ immersion continued to increase upon increasing the polymerization time beyond $12 \mathrm{~h}$, providing a brush-like regime of PHEMA brushes (empty squares). These observations reveal that the PHEMA brushes formed mushroomand brush-like regimes after immersion in $n$-hexane or $\mathrm{MeOH}$, respectively, consistent with the results of a previous study [37]. The thickness of the PHEMA brushes after immersion in the good solvent $(\mathrm{MeOH})$ increased nearly linearly upon increasing the polymerization time

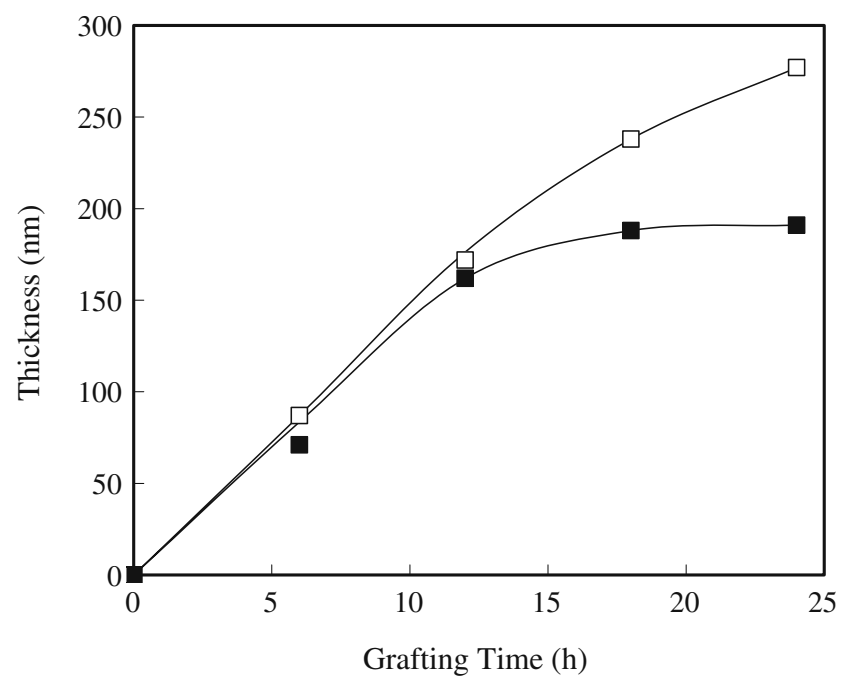

Fig. 5 Dependence of the thickness of the PHEMA layer, grown from the Si-BPOTS surface via ATRP 

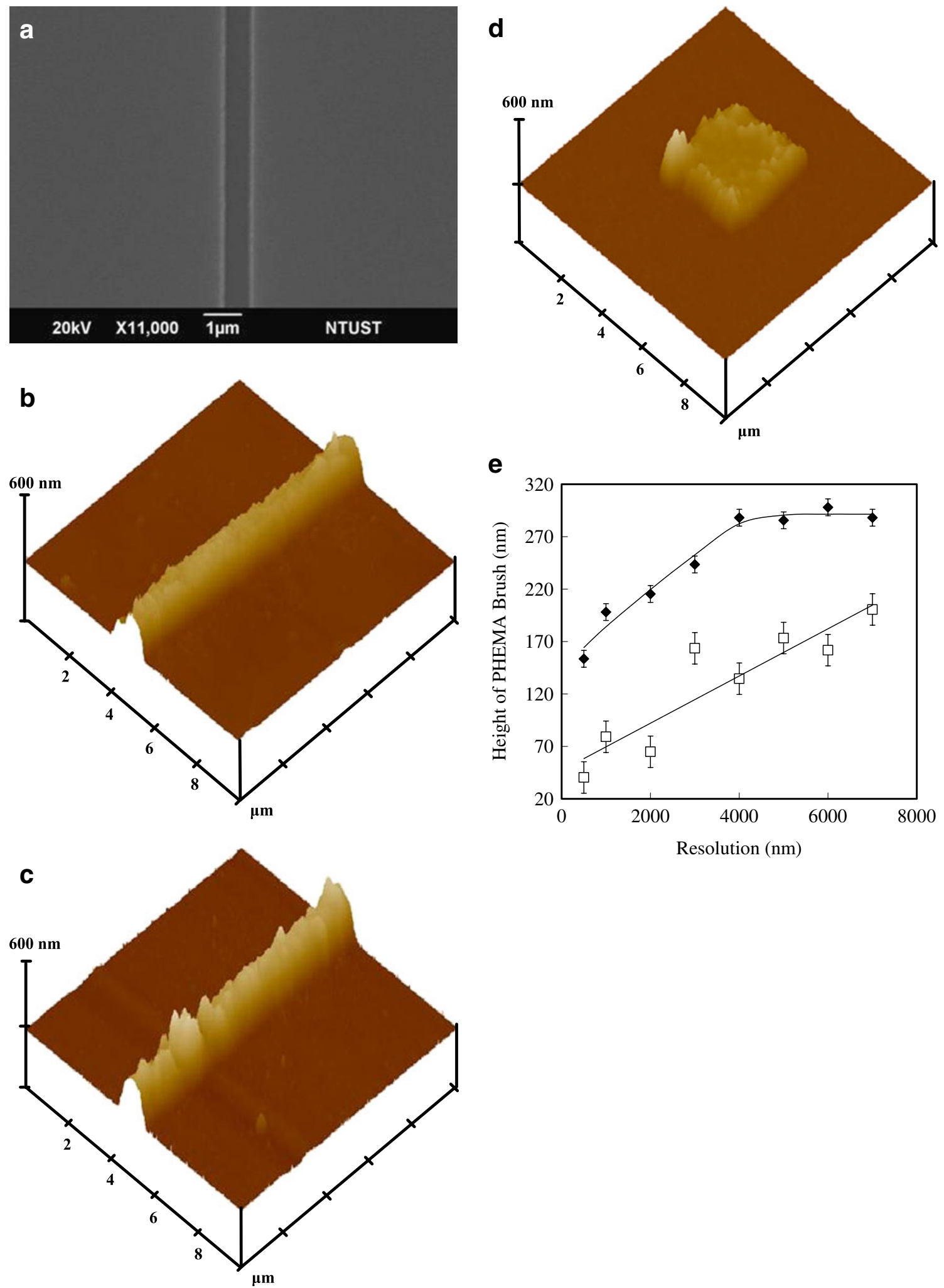

Fig. 6 a SEM image of a trench, having a resolution of $750 \mathrm{~nm}$, obtained through electron beam lithography. b-d AFM images of PHEMA brushes grafted from b, c 750-nm-resolution lines, obtained after polymerization for $24 \mathrm{~h}$ and immersion in $\mathbf{b} n$-hexane and $\mathbf{c}$ $\mathrm{MeOH}$ and d 2- $\mu \mathrm{m}$ holes, after polymerization for $24 \mathrm{~h}$ and

immersion in $\mathrm{MeOH}$. e Relationship between the height of the patterned PHEMA brushes and the resolution of lines (filled triangles) and dots (empty squares) on the Si-BPOTS surfaces after $\mathrm{MeOH}$ immersion 
because of the extension of the PHEMA brushes into a brush-like regime. Our results obtained after solvent immersion indicate that the process of surface-initiated ATRP of HEMA is controlled between two regimes for PHEMA brushes.

A previous study revealed that the molecular weight of a PHEMA brush on a $\mathrm{Si}$ wafer can be estimated by measuring the molecular weight of the corresponding free polymer [38]. We obtained additional evidence for the controlled polymerization from the "free" PHEMA formed from the free initiator. There is a linear relationship between $\ln \left(\left[\mathrm{M}_{0}\right] /[\mathrm{M}]\right)$ and time, where $\left[\mathrm{M}_{0}\right]$ is the initial monomer concentration and $[\mathrm{M}]$ is the monomer concentration. The concentration of the growing species remained constant; first-order kinetic was obtained. The number-average molecular weight of the "free" PHEMA increased linearly to $237 \mathrm{~kg} / \mathrm{mol}$ upon increasing the monomer conversion to 0.86 . The polydispersity index $\left(M_{\mathrm{w}} / M_{\mathrm{n}}\right)$ of the free PHEMA was approximately 1.2. Although we did not determine the exact molecular weight of the polymer grafted on the Si surface, we expected the molecular weight of the graft polymer to be proportional to that of the polymer formed in solution, i.e., we expected the molecular weight of the "free" PHEMA formed in solution to increase linearly with respect to the thickness of the PHEMA brushes for various polymerization times.

The final step in our strategy was the surface-initiated polymerization of HEMA onto the functionalized areas of a patterned SAM. The presence of reactive $\mathrm{OH}$ groups after OPT allowed their direct use in the polymerization step. We used lithography processes with positive photoresists to fabricate trenches and holes having resolutions ranging from $200 \mathrm{~nm}$ to $10 \mu \mathrm{m}$. Figure 6a displays an SEM image of a trench, patterned using e-beam lithography, having a resolution of $750 \mathrm{~nm}$ on the Si wafer. The PHEMA brushes were grafted onto the 750-nm-resolution trenches through ATRP for $24 \mathrm{~h}$. We used AFM to visualize the topographies of the resulting PHEMA brushes after their subsequent immersion in $n$-hexane and $\mathrm{MeOH}$. We grafted PHEMA brushes from the Si-BPOTS surfaces of the trenches and holes to form lines of PHEMA brushes. Figures $6 \mathrm{~b}, \mathrm{c}$ reveals that the HEMA polymer chains grafted for $24 \mathrm{~h}$ on the $\mathrm{Si}$ surface existed as distinctive overlayers after immersion in $n$-hexane and $\mathrm{MeOH}$, respectively. The patterned lines of the PHEMA brushes grafted for $24 \mathrm{~h}$ onto the 750-nm-resolution trenches were then immersed in solvent. Because of the presence of the mushroom- and brush-like regimes, the widths of the lines functionalized with PHEMA brushes had different resolutions after they had been immersed in $n$-hexane and $\mathrm{MeOH}$. Using this strategy, the limit of resolution of the PHEMA brushes patterned in lines approached $750 \mathrm{~nm}$. We observed imperfect line patterns for the PHEMA brushes when the trenches had dimensions of less than $750 \mathrm{~nm}$ prior to graft polymerization. The AFM images in Fig. 6b, c confirm the chemical amplification of the patterned $\mathrm{OH}$-functionalized SAM, forming spatially localized polymer brushes after immersion in $n$-hexane and $\mathrm{MeOH}$, respectively. The line pattern of the PHEMA brushes after immersion in $\mathrm{MeOH}$ displayed a more irregular overlayer on the surface because of the brush-like structure of the PHEMA units. After immersion in $n$-hexane, a regular line pattern formed because of inter-polymer hydrogen bonding within the mushroom-like PHEMA structures. The surface possessed its mushroom-like structure because of isotropic or nematic collapse of the PHEMA brushes in the presence of the poor solvent [39]. The line patterns of these PHEMA structures had different heights after treatment in $\mathrm{MeOH}$ and $n$-hexane because of the presence of the brush- and mushroom-like regimes, respectively. Again, these results confirm that the
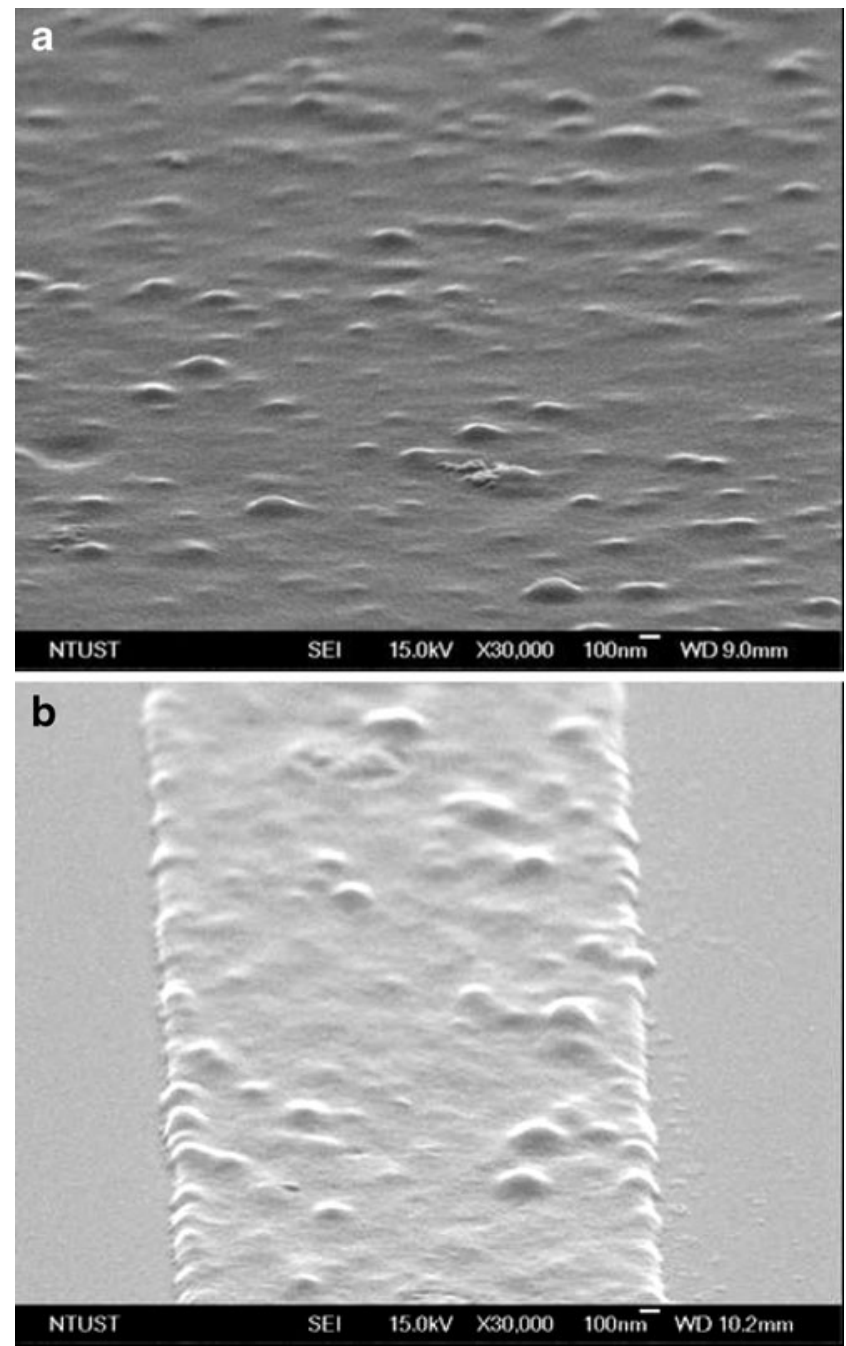

Fig. 7 SEM images of a PHEMA brushes without patterns and $\mathbf{b}$ the patterned PHEMA brushes grafted from $2-\mu \mathrm{m}$ trenches after polymerization for $24 \mathrm{~h}$ 
thickness of the polymer brushes changed after immersion in the good and poor solvents; furthermore, the grafting density and surface coverage varied accordingly, suggesting that they are suitable alternative parameters for calculating the thickness. Figure $6 \mathrm{~d}$ reveals that the dot pattern of PHEMA brushes grafted for $24 \mathrm{~h}$ on the Si surface existed as a distinctive overlayer after immersion in $\mathrm{MeOH}$. The patterned dots of PHEMA brushes were grafted for $24 \mathrm{~h}$ from holes having a resolution of $2 \mu \mathrm{m}$, and then the samples were immersed in solvent. Using this strategy, the limit of resolution of the patterned PHEMA brushes approached $750 \mathrm{~nm}$ for dot patterns. We observed imperfect line patterns for the PHEMA brushes when the holes had dimensions of less than $2 \mu \mathrm{m}$ prior to graft polymerization. Our observations suggest that the trenches were a richer
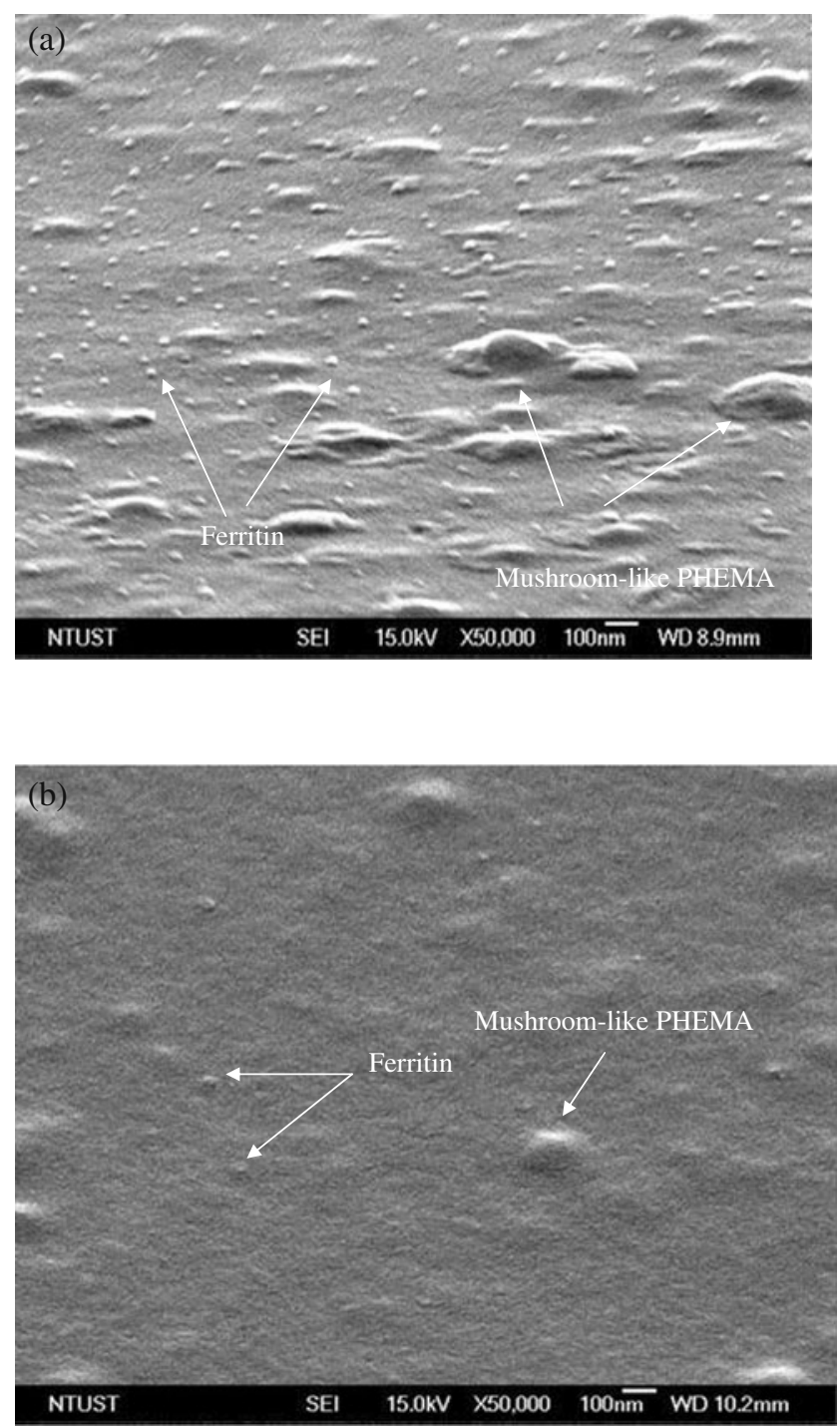

grafting site than the dots for the BPOTS treatment and OPT. Figure 6e presents the heights of the grafted PHEMA brushes, plotted with respect to the resolutions of the lines and dots onto the Si-BPOTS surfaces, after $\mathrm{MeOH}$ immersion. We observe approximately linear increases in the heights of the grafted PHEMA layer on the Si-BPOTS surface within the trenches upon increasing the resolution. The heights reached a plateau, indicating saturation of the grafting sites for ATPR, when the resolution was greater than $4 \mu \mathrm{m}$. In contrast, the height of the PHEMA brushes grafted from the holes increased upon increasing the resolution. The dot-patterned PHEMA brushes provided a more irregular overlayer on the surface because of the presence of unsaturated grafting sites on the Si-BPOTS surface. The considerable inaccuracy from measurement in
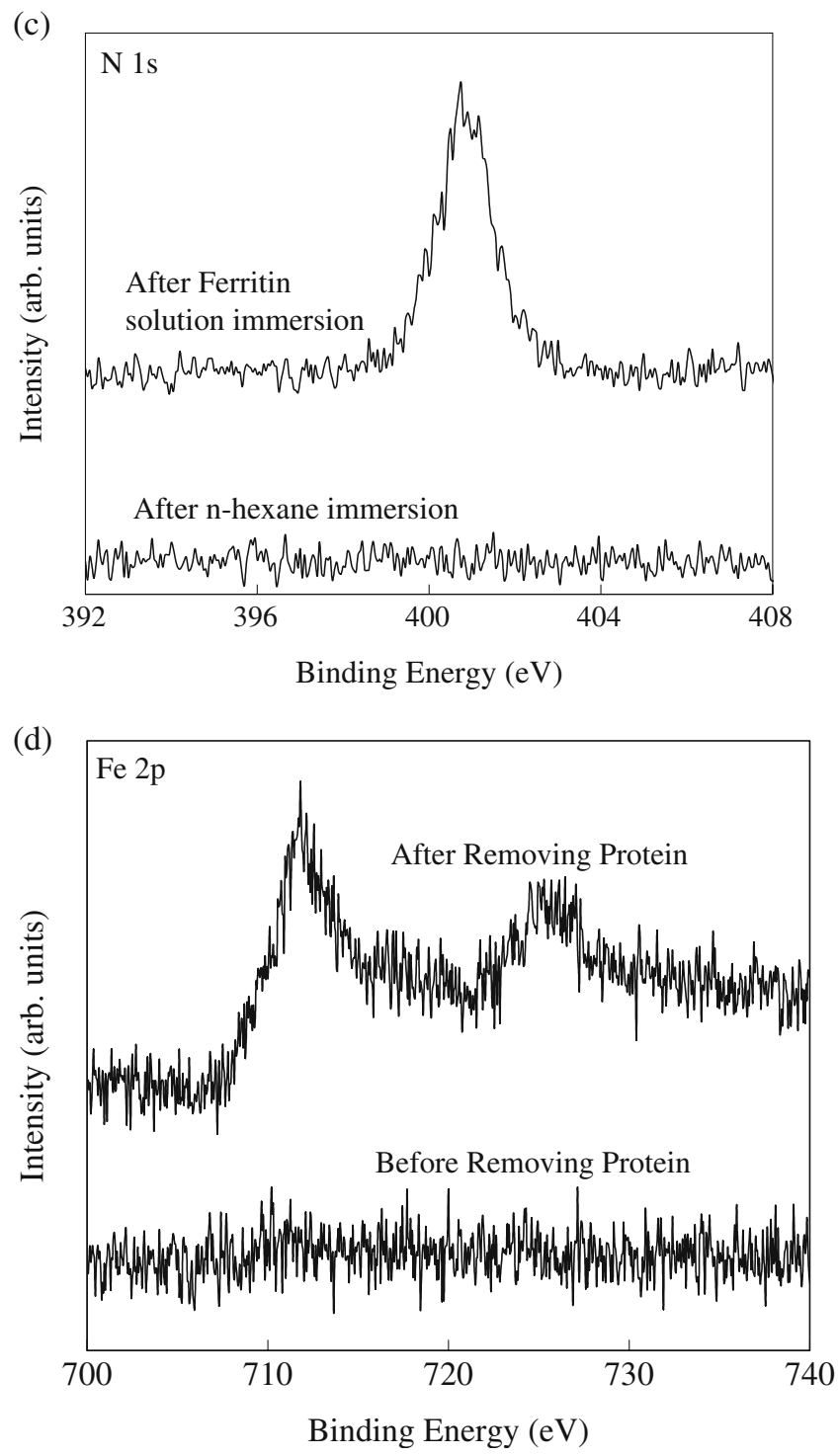

Fig. 8 a, b SEM images and c, d XPS N 1s core-level spectra of a PHEMA surface prepared through graft polymerization for $24 \mathrm{~h}$ and a, c immersion into a mixture of water and $\mathrm{MeOH}$ containing dispersed ferritin for $1 \mathrm{~h}$ and $\mathbf{b}$, $\mathbf{d}$ then immersion into $n$-hexane for $1 \mathrm{~h}$ 
Fig. 6e resulted from the ill-defined edges of the PHEMA brushes. SEM imaging revealed (Fig. 7a) the mushroomlike structure of this PHEMA thin film, where the formation of islands having radii of approximately $100 \mathrm{~nm}$ presumably resulted from the mushroom-like regime of the PHEMA brushes after they had been grafted for $24 \mathrm{~h}$ under vacuum in the SEM chamber. Figure $7 \mathrm{~b}$ presents SEM images of the patterned lines of PHEMA brushes grafted for $24 \mathrm{~h}$ from trenches having a resolution of $2 \mu \mathrm{m}$. The PHEMA brushes possessed collapsed structures in the vacuum of the SEM chamber; the mushroom-like structures on the surfaces of the patterned PHEMA brushes led to expansion of the PHEMA brush resolution to greater than $2 \mu \mathrm{m}$. The mushroom-like structures that formed on the PHEMA brush layers had radii ranging from 100 to $300 \mathrm{~nm}$, due to entanglement of the polymer chains under vacuum. This observation suggests that the PHEMA brushes possessed different structures when observed under atmospheric pressure (AFM) or vacuum (SEM).

\section{Absorption of ferritin onto patterned PHEMA brushes in various solvents}

We exploited the $\mathrm{OH}$ groups of the PHEMA brushes obtained after immersion in water as "tentacles" to capture ferritin from aqueous solution [9, 34]. In this study, the "tentacles" behavior of PHEMA brush was applied in various fluidic systems for biochip application. Figure 8a displays an SEM image of a PHEMA surface prepared through graft polymerization for $24 \mathrm{~h}$ and then injected aqueous solution containing dispersed ferritin through the surface by micropump. Ferritin complexes having radii of $13 \mathrm{~nm}$ are clearly visible on the PHEMA surface, which adsorbed on the surface for all regions because of the protein shell of ferritins. The surface presenting the patterned PHEMA brushes was under aqueous solution containing dispersed ferritin, such that the $\mathrm{OH}$ groups of the surface were raised into the solution. It is generally difficult to control protein adsorption on solid surfaces because nonspecific protein adsorption is often the first phenomenon that occurs when the surface comes into contact with a physiological environment. The PHEMA brush captured the ferritin units through entanglement of the $\mathrm{OH}$ groups of the PHEMA brushes with the protein sheaths of the ferritin complexes. Next, we injected $n$-hexane through the sample to transform the surface from a brush-like to a mushroomlike structure, causing the $\mathrm{OH}$ groups of the PHEMA brushes to become buried - along with the associated ferritin units - within the PHEMA thin film to form a hydrophilic domain in which the ferritin units were trapped.

After the $n$-hexane (poor solvent for PHEMA brush) was injected sequentially through the channel surface, Fig. $8 \mathrm{~b}$ reveals that only a few ferritin species remained on the
PHEMA surface; indeed, most of the ferritin complexes were now buried within the PHEMA thin film. We removed the ferritin species located on the PHEMA thin-film surface through degradation of the protein sheath; the buried ferritin units within the thin film were protected by the PHEMA brushes under these conditions. The absorbed ferritins on the patterned PHEMA brushes were covered by PHEMA brushes with mushroom-like regime in $n$-hexane fluid to maintain the dispersed ferritin regime. The "tentacles" behavior of PHEMA brushes for ferritins in various fluidic systems was defined. The "tentacles" on the surface captured the ferritin units through entanglement between the $\mathrm{OH}$ groups of the PHEMA brushes and the protein sheaths of the ferritin complexes. This sample was in an $n$-hexane solution to transform its surface units from brush-like to mushroom-like structures, causing the $\mathrm{OH}$ groups of the PHEMA brushes to become buried within PHEMA thin films to form hydrophilic domains, thereby trapping the ferritin units.

These observations confirmed our notion of PHEMA "tentacles" functioning under the influence of good and poor solvents. We used XPS to determine the chemical composition of the surfaces presenting ferritin units at various stages of the solvent treatment process (Fig. 8c, d). The $\mathrm{N}$ 1s core-level spectrum recorded after passing the aqueous ferritin solution over the PHEMA surface displayed a signal at a BE of approximately $400.7 \mathrm{eV}$, indicating that the ferritin units had become immobilized through interactions with the "tentacles" of the PHEMA brushes on the Si surface (Fig. 8c), consistent with the image in Fig. 8a. After treatment with $n$-hexane, the disappearance of the signal for the protein species at a $\mathrm{BE}$

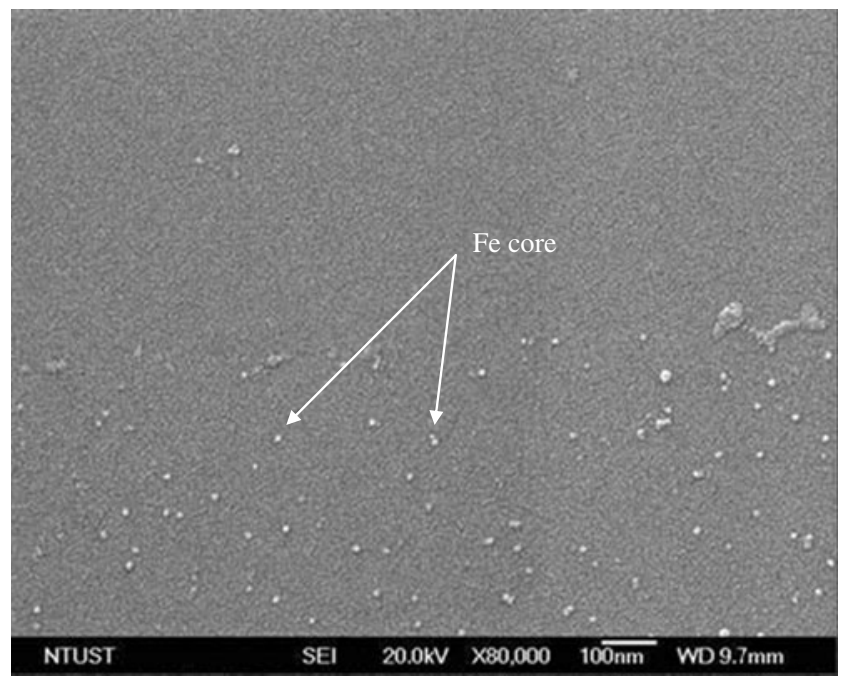

Fig. 9 Side-view SEM images ( $45^{\circ}$ oblique angle) of the Si surface, the PHEMA brushes grafted through 24-h polymerization from 750-nmwide trenches, and the captured ferritin cores after thermal treatment at $500{ }^{\circ} \mathrm{C}$ 
of $400 \mathrm{eV}$ confirms that the ferritin units were buried within the PHEMA thin film (Fig. 8b).

The peak components at BEs of approximately 711.8 and $725.7 \mathrm{eV}$ in the $\mathrm{Fe} 2 \mathrm{p}$ core-level spectrum of ferritin were absent in the spectrum of the PHEMA brush surface for all stages, suggesting that the ferritin protein sheaths concealed the Fe cores during the XPS measurement.

To verify this phenomenon, the PHEMA brushes and the ferritin protein sheaths buried within them were then pyrolyzed under $\mathrm{O}_{2}$ in an oven at approximately $500{ }^{\circ} \mathrm{C}$ to observe the ferrihydrite cores. The resulting surface displayed the two peak components at BEs of approximately 711.8 and $725.7 \mathrm{eV}$ (Fig. 8d), attributable to Fe-Fe and $\mathrm{Fe}-\mathrm{O}$ species, respectively, in the $\mathrm{Fe} 2 \mathrm{p}$ core-level spectrum [40]; in addition, the signal in the $\mathrm{N} 1 \mathrm{~s}$ core-level spectrum disappeared, confirming that this thermal treatment process decomposed the protein sheaths of the ferritin complexes. Next, we repeated the procedure using a $\mathrm{Si}$ wafer presenting the patterned PHEMA brushes. Figure 9 displays the SEM image we obtained from a patterned PHEMA thin film (grafted from 750-nm-wide trenches) after injecting first an aqueous solution of ferritin and then $n$-hexane through the PHEMA brush surface, cleaning the surface through protein degradation and then subjecting the wafer to pyrolysis at $500{ }^{\circ} \mathrm{C}$ to remove all organic compounds. The protein sheaths of the ferritin complexes were removed under these conditions, leaving the Fe core units (average radius of $7 \mathrm{~nm}$ ) on the trenches grafted from the PHEMA brushes. A few remnant PHEMA brushes are visible in Fig. 9 around the edges of the 750-nm patterned lines. The regions that had not featured PHEMA brushes presented very few ferritin cores, suggesting that only the PHEMA brushes had captured the ferritin complexes, which became buried within the thin film when treated with $n$-hexane. The absorbed ferritins on the bare silicon region surface were aggregated to macroparticles in $n$ hexane fluid and removed from the bare silicon region, displaying the distinct regions of bare silicon and dispersed ferritin surface. Our observations reveal that the capture and release of biomacromolecules from aqueous solution onto specific region of $\mathrm{Si}$ surfaces are possible when using PHEMA brushes as smart "tentacles" in various solvent fluids.

\section{Conclusions}

We have used a "grafting from" system with ATRP to prepare well-defined, dense PHEMA brushes on Si wafers. This novel strategy allows the fabrication of patterned polymer brushes from Si surfaces using commercial semiconductor processes. The key feature of this approach is the use of surface-initiated polymerization through OPT to chemically amplify patterned SAMs into macromolecular films. It provides patterned polymeric thin films having surface dimensions that approach the nanoscale. We established the ability of the PHEMA chains to function as "tentacles" for the capture of ferritin complexes from aqueous solution. The protein sheaths of the ferritin units were captured specifically on the PHEMA-patterned areas of the Si surface in aqueous solvents. We are extending this strategy toward the development of protein-detecting devices and are exploring the magnetic properties of $\mathrm{Fe}$ cores bound to specific areas on Si wafers.

Acknowledgment We thank the National Nano Device Laboratory for its financial support of the electron beam lithography system.

Open Access This article is distributed under the terms of the Creative Commons Attribution Noncommercial License which permits any noncommercial use, distribution, and reproduction in any medium, provided the original author(s) and source are credited.

\section{References}

1. Kin MH, Wei YL, Chun HW, Pei L (2010) Colloid Polym Sci 288:1503-1523

2. Wang JY, Chen W, Liu AH, Lu G, Zhang G, Zhang JH, Yang BJ (2002) Am Chem Soc 124:13358-13359

3. Xu FJ, Zhong SP, Yung LYL, Kang ET, Neoh KG (2004) Biomacromolecules 5:2392-2403

4. Kizhakkedathu JN, Norris-Jones R, Brooks DE (2004) Macromolecules 37:734-743

5. Ma H, Hyun J, Stiller P, Chilkoti A (2004) Adv Mater 16:338-341

6. Iwata R, Suk-In P, Hoven VP, Takahara A, Akiyoshi K, Iwasaki Y (2004) Biomacromolecules 5:2308-2314

7. Gong X, Wu Ci, To N (2010) Colloid Polym Sci 288:1167-1172

8. Chen JK, Chan CH, Chang FC (2008) App Phys Lett 92:053108

9. Chan CH, Chen JK, Chang FC (2008) Sens Actuators B 13:327-332

10. Ohno K, Morinaga T, Takeno S, Tsujii Y, Fukuda T (2007) Macromolecules 40:9143-9150

11. Ishida N, Biggs S (2007) Macromolecules 40:9045-9052

12. Elmahdy MM, Synytska A, Drechsler A, Gutsche C, Uhlmann P, Stamm M, Kremer F (2009) Macromolecules 42:9096-9102

13. Kegler K, Salomo M, Kremer F (2007) Phys Rev Lett 98:058304

14. Chen J-K, Li J-Y (2010) Appl Phys Lett 97:063701

15. Chen J-K, Li J-Y (2010) Sens Actuators B 150:314-320

16. Senaratne W, Andruzzi L, Ober CK (2005) Biomacromolecules 6:2427-2448

17. Toscano A, Santore MM (2006) Langmuir 22:2588-2597

18. Prime KL, Withesides GM (1991) Science 252:1164-1167

19. Lee JH, Lee HB, Andrade JH (1995) Prog Polym Sci 20:1043-1079

20. Salloum DS, Schlenoff JB (2004) Biomacromolecules 5:1089-1096

21. Kegler K, Konieczny M, Dominguez-Espinosa G, Gutsche C, Salomo M, Kremer F, Likos CN (2008) Phys Rev Lett 100:118302

22. Valenti LE, Fiorito PA, García CD, Giacomelli CE (2007) J Colloid Interface Sci 307:349-356

23. Yoshikawa C, Goto A, Tsujii Y, Fukuda T, Kimura T, Yamamoto K, Kishida A (2006) Macromolecules 39:2284-2290

24. Henzler K, Rosenfeldt S, Wittemann A, Harnau L, Finet S, Narayanan T, Ballauff M (2008) Phys Rev Lett 100:158301

25. Chen JK, Hsieh CY, Huang CF, Li PM, Kuo SW, Chang FC (2008) Macromolecules 41:8729-8736 
26. Hess DM, Naik RR, Rinaldi C, Tomczak MM, Watkins JJ (2009) Chem Mater 21:2125-2129

27. Thiel EC (1987) Annu Rev Biochem 56:289-315

28. Chen J-K, Chen ZY (2011) J Colloid Interface Sci (in press)

29. Stoykovich MP, Müller M, Kim SO, Solak HH, Edwards EW, de Pablo JJ, Nealey PF (2005) Science 308:1442-1446

30. Matyjaszewski K, Miller PJ, Shukla N, Immaraporn B, Gelman A, Luokala BB, Siclovan TM, Kickelbick G, Vallant T, Hoffmann H, Pakula T (1999) Macromolecules 32:8716-8724

31. Van Oss CJ, Ju L, Chaudhury MK, Good RJJ (1989) Colloid Interface Sci 128:313-319

32. Fowkes FMJ (1962) Phys Chem 66:382

33. Drummond CJ, Chan DYC (1997) Langmuir 13:3890-3895
34. Chen JK, Chen ZY, Lin HC, Hong PD, Chang FC (2009) ACS Appl Mater Interfaces 1:1525-1532

35. Chen JK, Hsieh CY, Huang CF, Li PMJ (2009) Colloid Interface Sci 338:428-434

36. Chen JK, Ko FH, Hsieh KF, Wang CF, Chou CT, Chang FCJ (2004) Vac Sci Technol B 22:3233-3241

37. Chen J-K, Zhuang A-L (2010) J Phys Chem C 114:11801-11809

38. Rowe-Konopacki MD, Boyes SG (2007) Macromolecules 40:879-888

39. Lu G, Li Y-M, Lu C-H, Xu Z-Z (2010) Colloid Polym Sci 288:1445-1455

40. Martin KC, Villano SM, McCurdy PR, Zapien DC (2003) Langmuir 19:5808-5812 